\author{
Wolfram Windisch \\ Klaus Freidel \\ Bernd Schucher \\ Hansjörg Baumann \\ Matthias Wiebel \\ Heinrich Matthys \\ Franz Petermann
}

\section{Evaluation of health-related quality of life using the MOS 36-Item Short-Form Health Status Survey in patients receiving noninvasive positive pressure ventilation}

Received: 11 April 2002

Accepted: 10 December 2002

Published online: 5 March 2003

(C) Springer-Verlag 2003

W. Windisch $(\bullet) \cdot$ H. Matthys

Department of Pneumology,

University Hospital Freiburg,

Killianstrasse 5, 79106 Freiburg, Germany

e-mail: windisch@med1.ukl.uni-freiburg.de

Tel.: +49-761-2703706

Fax: +49-761-2703704

K. Freidel

St. Josefs Hospital, Wiesbaden, Germany

B. Schucher

Abteilungen Pneumologie,

Beatmungsmedizin und Schlaflabor,

Evangelisches Krankenhaus

Göttingen-Weende,

Bovenden-Lenglern, Germany

H. Baumann

Zentrum für Pneumologie

und Thoraxchirurgie,

Krankenhaus Großhansdorf,

Großhansdorf, Germany

M. Wiebel

Thoraxklinik-Heidelberg,

Heidelberg, Germany

F. Petermann

Rehabilitation Research Center,

University of Bremen,

Bremen, Germany

\author{
Abstract Objective: To collect \\ benchmark data on the MOS 36-Item \\ Short-Form Health Status Survey \\ (SF-36) in patients receiving noninva- \\ sive positive pressure ventilation and \\ to examine whether health-related \\ quality of life is influenced by the un- \\ derlying disease or by physical pa- \\ rameters. Design and setting: Multi- \\ centric clinical cross-sectional trial in \\ four general wards specialized in non- \\ invasive positive pressure ventilation. \\ Patients and participants: 226 pa- \\ tients (78 chronic obstructive \\ pulmonary disease, 57 kyphoscolio- \\ sis, 20 posttuberculosis sequelae, \\ 17 Duchenne muscular dystrophy, \\ 13 polyneuropathy, 13 myopathy, \\ 6 amyotrophic lateral sclerosis, \\ 12 obesity-hypoventilation syndrome, \\ 4 poliomyelitis sequelae, 3 phrenic \\ nerve lesion, 3 central hypoventila- \\ tion syndrome) who used noninvasive \\ positive pressure ventilation for home \\ mechanical ventilation. Measure- \\ ments and results: Health-related \\ quality of life as assessed by the \\ SF-36 was lower than in the general \\ population. Overall the Physical
}

Component Summary (PCS) was significantly lower than the general population norm; the Mental Component Summary (MCS) was also reduced but less markedly. Patients with chronic obstructive pulmonary disease were more impaired in MCS than those with kyphoscoliosis. PCS was significantly associated with age. Gender, lung function, and arterial blood gas values were not significant predictors of health-related quality of life. Conclusions: Benchmark SF-36 data in patients receiving noninvasive positive pressure ventilation are given. Although physical health is significantly impaired in these patients, this does not necessarily lead to mental limitation, and mental health is influenced by the underlying disease, but not by physical parameters.

Keywords Chronic obstructive pulmonary disease $\cdot$ Chronic respiratory failure $\cdot$ Health-related quality of life $\cdot$ Home mechanical ventilation · Kyphoscoliosis . Noninvasive positive pressure ventilation

\section{Introduction}

Noninvasive positive pressure ventilation (NPPV) delivered by a facial mask is a well established therapeutic option for patients with hypercapnic chronic respiratory failure (CRF) due to chest wall deformities, neuromuscular diseases, and chronic obstructive pulmonary disease (COPD), thus improving objective parameters such as gas exchange, respiratory pump function, and sleep quality $[1,2,3,4,5,6]$. When NPPV is used for home mechanical ventilation, it is a time- and cost-intensive therapy, and patients receiving home mechanical ventilation usually suffer from end-stage disease with objectively severe limitations of daily living. Several studies have been conducted in the past decade to evaluate health-related quality of life (HRQL) in these patients $[3,4,7,8$, 
9, 10, 11], since evaluation of HRQL has become steadily more essential in health care practice and research during the past two decades to evaluate the human and financial costs and benefits of modern medical techniques $[12,13,14]$. Although mild to moderate improvements in HRQL have been reported in patients with hypercapnic CRF due to COPD following NPPV [3, 7, 9, 10], patients with chest wall deformities are reported to have a better physical function than those with COPD [4].

The Medical Outcomes Study 36-Item Short-Form Health Status Survey (SF-36) developed by Ware and Sherbourne [15] and Ware et al. [16] is a well validated and widely used multipurpose survey of general health status with results of both healthy reference population and specific disease groups being available. In addition, the SF-36 has been shown to be eligible for HRQL assessment in intensive care unit populations $[17,18,19$, 20, 21]. However, detailed data using the SF-36 in patients receiving NPPV do not exist, and the number of patients included in most studies investigating HRQL in patients receiving NPPV is small. Therefore, we conducted a multicentric cross-sectional trial aimed at providing benchmark SF-36 data in patients with CRF receiving NPPV, thereby testing whether HRQL is different in patients with obstructive and restrictive ventilatory disorders.

\section{Materials and methods}

\section{Patients}

Patients receiving NPPV consecutively enrolled in the study were recruited from four German hospitals: Krankenhaus GöttingenWeende, Lenglern $(n=93)$, Krankenhaus Großhansdorf $(n=60)$, Thoraxklinik, Heidelberg $(n=51)$, and the University Hospital of Freiburg $(n=30)$. Only patients with stable disease who were hospitalized for a routine check of home mechanical ventilation (1-2 days) using a nasal or full-face mask were studied. Patients who had been tracheotomized and patients who were hospitalized for acute exacerbation or for first establishment of NPPV were excluded from the study.

Eight patients did not complete the questionnaire and were excluded from the study. Characteristics of the remaining 226 patients enrolled are given in Table 1. Patients with COPD $(n=78)$ and with kyphoscoliosis $(n=57)$ were the largest homogeneous subgroups enrolled and are therefore described separately. The remaining 91 patients were heterogeneous concerning the underlying cause of CRF and were therefore subsumed in one group labeled miscellaneous disorders including patients with posttuberculosis sequelae $(n=20)$, obesity-hypoventilation syndrome $(n=12)$, poliomyelitis sequelae $(n=4)$, phrenic nerve lesion $(n=3)$, central hypoventilation syndrome $(n=3)$, and patients with neuromuscular diseases: Duchenne muscular dystrophy $(n=17)$, polyneuropathy $(n=13)$, myopathy $(n=13)$, and amyotrophic lateral sclerosis $(n=6)$. All patients enrolled were fully conversant with NPPV and were clinically stable with no signs of acute exacerbation. In addition, 82 patients (50 COPD, 12 kyphoscoliosis, 20 miscellaneous disorders) were on long-term oxygen therapy over $16.91 \pm 6.68 \mathrm{~h} /$ day.

\section{Study design}

The study protocol was approved by the institutional review board for human studies and was carried out in accordance with the ethical standards of the Declaration of Helsinki. Informed written consent was obtained from all patients. Lung function parameters (Masterlab, Jaeger, Würzburg, Germany) were measured in all patients. Full bodyplethysmography was available in all but 32 patients with neuromuscular disease; in these patients spirometry was performed. Arterial blood gas measurements were drawn from the radial artery both while on ventilation for at least $4 \mathrm{~h}$ and during subsequent spontaneous breathing of room air for at least $4 \mathrm{~h}$ after cessation of ventilation.

Patients were asked to fill in the SF-36 which consists of eight subscales measuring different aspects of health status. Each subscale produces a standardized score between 0 and 100 , with lower scores indicating poorer health or higher disability. The scales can be aggregated to two summary measures: the Physical Component Summary (PCS) and the Mental Component Summary (MCS). The present study used the German version of SF-36 [22, 23]. General norms of the German population are available from the responses of 2,914 representatively selected participants [23] Norms are provided by age cohort, gender, and disease (i.e., subsample of patients with chronic lung disease, $n=171$; age $49.27 \pm 19.57$ years, $63.1 \%$ women). In addition to the administration of the SF-36, patients filled in a new questionnaire for its validation which has been specifically developed for patients with severe respiratory insufficiency, the Severe Respiratory Insufficiency (SRI) Questionnaire [24] (Windisch et al., in preparation).

\section{Statistical analysis}

Statistical analysis was performed using SPSS 9.0 for windows NT (SPSS, Chicago, Ill., USA). Descriptive data are presented as mean \pm standard deviation. For comparisons of the study group with norms the $t$ test was used. Group comparisons (underlying disease and gender) were performed by multivariate analysis of covariance (MANCOVA), controlling for age, $\mathrm{PaO}_{2}$ breathing room air, $\mathrm{PaCO}_{2}$ breathing room air, and forced expiratory volume in $1 \mathrm{~s}\left(\mathrm{FEV}_{1}\right)$. First, MANCOVA was performed using PCS and MCS as dependent variables. Second, the eight subscales of the SF-36 were used as dependent variables. Both multivariate and univariate tests were performed. Statistical significance was set at a $p$ value less than 0.05 . However, only patients with COPD and kyphoscoliosis were included in the MANCOVA; patients with miscellaneous disorders were not included due to the heterogeneity of this group. In addition, smaller subgroups of patients such as those with Duchenne muscular dystrophy were also excluded from
Table 1 Patient's characteristics $(C O P D$ chronic obstructive pulmonary disease, $N P P V$ noninvasive positive pressure ventilation)

\begin{tabular}{lcll}
\hline Diagnostic group & All patients $(n=226)$ & COPD $(n=78)$ & Kyphoscoliosis $(n=57)$ \\
\hline Age (years) & $57.3 \pm 14.0$ & $60.9 \pm 9.6$ & $56.6 \pm 11.3$ \\
Sex: M/F & $118 / 108$ & $25 / 53$ & $42 / 15$ \\
Duration of NPPV (months) & $23.7 \pm 31.9$ & $16.6 \pm 22.8$ & $38.1 \pm 36.5$ \\
Daily ventilation (h/day) & $9.0 \pm 3.4$ & $9.3 \pm 3.4$ & $8.9 \pm 2.5$ \\
\hline
\end{tabular}


Table 2 Body mass index (BMI), lung function, and arterial blood gas measurements in patients receiving NPPV $(n=226)(F V C$ forced vital capacity, $F E V_{1}$ forced expiratory volume in $1 \mathrm{~s}, T L C$ total lung capacity, $\mathrm{PaCO}_{2}$ partial pressure of carbon dioxide, $\mathrm{PaO}_{2}$ partial pressure of oxygen, $C O P D$ chronic obstructive pulmonary disease, $N P P V$ noninvasive positive pressure ventilation)

\begin{tabular}{llcl}
\hline & All patients & COPD & Kyphoscoliosis \\
\hline BMI & $26.4 \pm 7.2$ & $27.9 \pm 6.6^{*}$ & $24.4 \pm 5.5^{*}$ \\
FVC (\% pred) & $48.4 \pm 18.2$ & $56.4 \pm 13.0^{*}$ & $39.6 \pm 13.8^{*}$ \\
FEV $_{1}$ (\% pred) & $38.1 \pm 17.4$ & $31.4 \pm 12.6^{*}$ & $36.6 \pm 13.9$ \\
FEV $_{1} / \mathrm{FVC}(\%)$ & $64.4 \pm 21.5$ & $43.0 \pm 11.9^{*}$ & $75.5 \pm 15.4^{*}$ \\
$\mathrm{TLC}^{(\%}$ pred) & $81.4 \pm 33.7$ & $110.3 \pm 27.7^{*}$ & $52.6 \pm 17.5^{*}$ \\
$\mathrm{PaCO}_{2}$ (room air) & $44.2 \pm 6.5$ & $45.9 \pm 7.0^{*}$ & $44.1 \pm 5.3$ \\
$\mathrm{PaCO}_{2}$ (NPPV) & $38.6 \pm 6.3$ & $42.1 \pm 6.2^{*}$ & $37.2 \pm 4.9^{*}$ \\
$\mathrm{PaCO}_{2}$ (room air) & $65.8 \pm 11.2$ & $58.1 \pm 9.7 *$ & $67.6 \pm 9.1$ \\
$\mathrm{PaCO}_{2}$ (NPPV) & $79.0 \pm 17.4$ & $77.9 \pm 20.8$ & $76.7 \pm 11.4$ \\
pH & & & \\
pH (room air) & $7.41 \pm 0.05$ & $7.42 \pm 0.04$ & $7.41 \pm 0.05$ \\
pH (NPPV) & $7.46 \pm 0.06$ & $7.44 \pm 0.05^{*}$ & $7.47 \pm 0.06$
\end{tabular}

$* p<0.05$ vs. mean of the other patients (COPD vs. kyphoscoliosis); contrast tests in the procedure of univariate analysis of variance conducted only if in the overall test was significant.

the MANCOVA when tested for diagnosis due to the reduced number of patients included.

\section{Results}

The daily use of ventilation was comparable in patients with COPD and kyphoscoliosis (Table 1). However, patients with Duchenne muscular dystrophy used the ventilator $11.6 \pm 5.6 \mathrm{~h} / \mathrm{day}$, while those with posttuberculosis sequelae used the ventilator $7.6 \pm 2.7 \mathrm{~h} /$ day. Four patients spent more than $20 \mathrm{~h} /$ day on the ventilator: one had COPD, one amyotrophic lateral sclerosis, and two Duchenne muscular dystrophy. Patients with Duchenne muscular dystrophy (age 30.1 \pm 11.4 years) were younger than the remaining patients with neuromuscular diseases (age 51.8 \pm 15.4 years). The oldest patients were those with posttuberculosis sequelae (70.2 \pm 5.6 years). Patients with kyphoscoliosis and those with Duchenne muscular dystrophy spent the longest period on NPPV with $38.1 \pm 36.5$ and $34.1 \pm 60.1$ months, respectively.

Diagnostic data are given in Table 2. Patients with COPD had the lower $\mathrm{PaO}_{2}$ when breathing room air than all other patients. Mild hypocapnia during ventilation was achieved in all patients except those with COPD. However, $\mathrm{PaCO}_{2}$ in patients with hypercapnic COPD had been decreased to normocapnic values while on ventilation, since all patients had been hypercapnic prior to NPPV. Accordingly, $\mathrm{PaCO}_{2}$ breathing room air revealed normocapnia to mild hypercapnia in all patients with highest $\mathrm{PaCO}_{2}$ values in patients with COPD. In addition, there was a significant correlation between $\mathrm{PaCO}_{2}$ during ventilation and $\mathrm{PaCO}_{2}$ when breathing room air following ventilation in all patients $(r=0.463, p<0.0001)$.

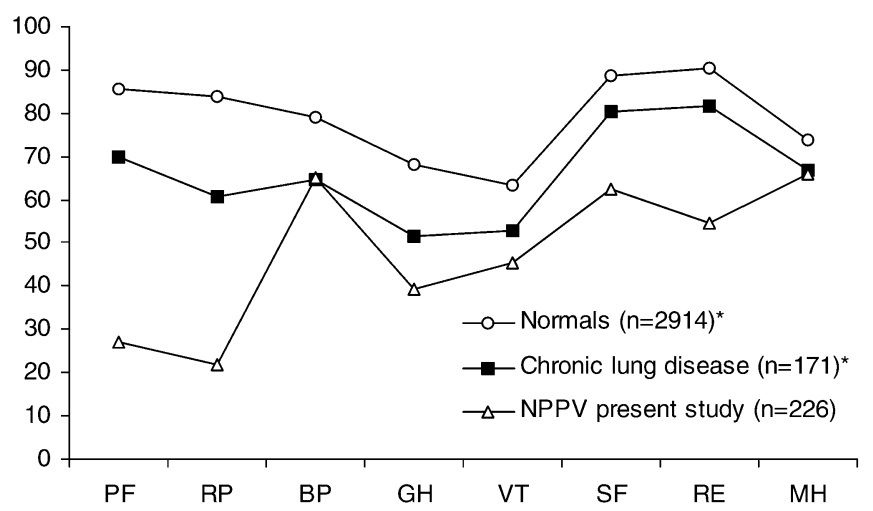

Fig. 1 Domains of the SF-36 in normal subjects (Normals), patients with chronic lung disease, and patients receiving non-invasive positive pressure ventilation (NPPV). Each subscale produces a standardized score between 0 and 100, with lower scores indicating poorer health or higher disability. $\mathrm{PF}=$ Physical Functioning, RP = Role-Physical, $\mathrm{BP}=$ Bodily Pain, $\mathrm{GH}=$ General Health, $\mathrm{VT}=$ Vitality, $\mathrm{SF}=$ Social Functioning, $\mathrm{RE}=$ Role-Emotional, $\mathrm{MH}=$ Mental Health. *Adopted from reference [23]

Table 3 SF-36 scale scores in patients receiving NPPV $(n=226)$ ( $P F$ Physical Functioning, $R P$ Role-Physical, $B P$ Bodily Pain, $G H$ General Health, VT Vitality, SF Social Functioning, $R E$ RoleEmotional, $M H$ Mental Health, PCS Physical Component Summary, MCS Mental Component Summary, NPPV noninvasive positive pressure ventilation)

\begin{tabular}{lllc}
\hline & Mean \pm SD & Percentiles: $25-50-75$ & Range \\
\hline PF & $27.04 \pm 24.69$ & $5-20-40$ & $0-100$ \\
RP & $21.94 \pm 35.83$ & $0-0-25$ & $0-100$ \\
BP & $65.23 \pm 31.80$ & $41-67-100$ & $0-100$ \\
GH $^{a}$ & $39.44 \pm 19.67$ & $25-37-52$ & $0-100$ \\
VTa $^{a}$ & $45.60 \pm 20.72$ & $30-45-60$ & $0-100$ \\
SF & $62.50 \pm 30.05$ & $37-63-87$ & $0-100$ \\
RE & $54.75 \pm 46.17$ & $0-67-100$ & $0-100$ \\
MH & $65.77 \pm 20.94$ & $52-68-80$ & $8-100$ \\
PCS $^{a}$ & $29.96 \pm 9.00$ & $23.80-28.77-35.01$ & $13.70-55.75$ \\
MCS $^{a}$ & $48.17 \pm 11.76$ & $38.40-49.51-57.93$ & $18.08-71.56$ \\
\hline
\end{tabular}

a Normally distributed

Self-administration of the SF-36 was possible in 219 patients, but seven (one with COPD, six with neuromuscular diseases) required administration by an interviewer in person (Fig. 1). Table 3 shows that the SF-36 mean scores for PCS and MCS in patients receiving NPPV. PCS $(29.96 \pm 9.00)$ was significantly lower than in the general population $(50.21 \pm 10.24, \quad p<0.001)$ and also compared to the reference population group with chronic lung diseases $(42.64 \pm 11.50, p<0.001)$ [23]. MCS of the overall study group $(48.17 \pm 11.76)$ was also significantly lower than in the general population $(51.54 \pm 8.14$, $p<0.01$ ), but did not differ significantly from the reference population group with chronic lung diseases (46.94 \pm 12.50$)$ [23]. In the study group patients with kyphoscoliosis had a higher MCS than patients with COPD 
Table 4 Impact on HRQL (SF-36) in patients receiving NPPV: MANCOVA with PCS and MCS as dependent variables and including covariates: age, $\mathrm{FEV}_{1}$ (\% pred.), $\mathrm{PaO}_{2}$ (room air), and $\mathrm{PaCO}_{2}$ (room air) (HRQL health-related quality of life, $P C S$ Physical Component Summary, MCS Mental Component Summary, $N P P V$ noninvasive positive pressure ventilation)

\begin{tabular}{|c|c|c|c|c|c|c|c|c|c|}
\hline \multirow[t]{3}{*}{ Design } & \multicolumn{3}{|c|}{ Multivariate tests } & \multicolumn{6}{|c|}{ Univariate tests ${ }^{\mathrm{a}}$} \\
\hline & \multirow[t]{2}{*}{$F$} & \multirow[t]{2}{*}{ df } & \multirow[t]{2}{*}{$p$} & \multicolumn{3}{|l|}{ PCS } & \multicolumn{3}{|l|}{ MCS } \\
\hline & & & & $F$ & df & $p$ & $F$ & df & $p$ \\
\hline Diagnosis ${ }^{\mathrm{b}}$ & 4.02 & 2 & 0.02 & 0.08 & 1 & 0.78 & 7.78 & 1 & 0.01 \\
\hline Covariatec: age & 4.25 & 2 & 0.02 & 7.00 & 1 & 0.01 & 0.92 & 1 & 0.34 \\
\hline Gender & 1.83 & 2 & 0.17 & - & - & - & - & - & - \\
\hline
\end{tabular}

a Only listed if multivariate test was significant

${ }^{\mathrm{b}}$ COPD vs. kyphoscoliosis

${ }^{c}$ Only listed if significant
Table 5 SF-36 scale scores in patients receiving noninvasive positive pressure ventilation [chronic obstructive pulmonary disease $(C O P D, n=78)$ and kyphoscoliosis $(n=57)]$ and in reference populations ( $P F$ Physical Functioning, $R P$ Role-Physical, $B P$ Bodily
Pain, GH General Health, VT Vitality, SF Social Functioning, RE Role-Emotional, $M H$ Mental Health, PCS Physical Component Summary, MCS Mental Component Summary)

\begin{tabular}{|c|c|c|c|c|c|}
\hline & General population $^{\mathrm{a}}$ & Chronic lung disease ${ }^{a}$ & COPD & Kyphoscoliosis & $p^{\mathrm{b}}$ \\
\hline $\mathrm{PF}$ & $85.71 \pm 22.10$ & $69.88 \pm 26.60$ & $29.80 \pm 24.31$ & $34.24 \pm 23.86$ & 0.69 \\
\hline RP & $83.70 \pm 31.73$ & $60.62 \pm 40.48$ & $16.91 \pm 31.28$ & $29.09 \pm 41.04$ & 0.12 \\
\hline $\mathrm{BP}$ & $79.08 \pm 27.38$ & $64.61 \pm 29.74$ & $61.85 \pm 33.14$ & $67.73 \pm 27.75$ & 0.10 \\
\hline GH & $68.05 \pm 20.15$ & $51.58 \pm 21.50$ & $36.59 \pm 17.61$ & $42.59 \pm 18.73$ & 0.08 \\
\hline VT & $63.27 \pm 18.40$ & $52.98 \pm 21.07$ & $40.49 \pm 18.85$ & $52.46 \pm 20.55$ & $<0.01$ \\
\hline SF & $88.76 \pm 18.40$ & $80.35 \pm 23.49$ & $56.09 \pm 29.04$ & $72.15 \pm 28.05$ & $<0.01$ \\
\hline $\mathrm{RE}$ & $90.35 \pm 25.62$ & $81.75 \pm 33.98$ & $47.22 \pm 46.05$ & $71.24 \pm 41.64$ & 0.01 \\
\hline MH & $73.88 \pm 16.38$ & $66.75 \pm 19.05$ & $62.35 \pm 19.55$ & $69.77 \pm 19.79$ & 0.02 \\
\hline PCS & $50.21 \pm 10.24$ & $42.64 \pm 11.50$ & $30.00 \pm 8.33$ & $32.24 \pm 10.67$ & 0.78 \\
\hline MCS & $51.54 \pm 8.14$ & $46.94 \pm 12.50$ & $45.32 \pm 10.34$ & $53.05 \pm 10.24$ & 0.01 \\
\hline
\end{tabular}

a From [23]

b MANCOVA: univariate tests including the SF-36 subscales and the two summary measures (PCS and MCS) as dependent variables (COPD vs. kyphoscoliosis); for further information see text

$(p<0.01)$ (Tables 4, 5). Interestingly, patients with Duchenne muscular dystrophy had the highest MCS (59.60 \pm 5.60$)$, which was even higher than MCS of the general population $(51.54 \pm 8.14)$. PCS of patients with COPD was comparable to PCS of patients with kyphoscoliosis (Tables 4, 5). Men and women did not differ in summary measures.

In addition to the results of the summary measures, the multivariate test of the MANCOVA revealed different values for patients with COPD and those with kyphoscoliosis when all subscales of the SF-36 were included as dependent variables $(F=2.79, \mathrm{df}=8, p<0.01)$. Using the univariate tests values of four subscales were significantly higher in patients with kyphoscoliosis than in those with COPD (Table 5): Vitality, Social Functioning, Role-Emotional, and Mental Health. This is in accordance with the results from the analysis including the summary measures with a significantly higher MCS in patients with kyphoscoliosis, since MCS is derived from these four subscales $[15,16]$. In contrast, PCS is derived from the other four subscales: Physical Functioning, Role-Physical, Bodily Pain, and General Health [15, 16], and there were no significant differences in patients with
COPD and those with kyphoscoliosis either in overall PCS or its four subscales. The patient's age had a slight impact on HRQL, since Physical Functioning decreased with age $(r=-0.213, p<0.05)$. Other tested covariates $\left(\mathrm{FEV}_{1}, \mathrm{PaO}_{2}, \mathrm{PaCO}_{2}\right)$ had no effect on SF-36 components. In addition, gender was not predictive for the subscales of the SF-36.

\section{Discussion}

In the present study the SF-36 revealed that overall HRQL is significantly lower in patients receiving longterm NPPV than in the general population. The impairment is due primarily to limitations in physical health which is not surprising, since patients receiving home mechanical ventilation usually suffer from end-stage disease with severe physical handicaps. Mental health was also lower than in the general population, but this was less marked, and mental health in patients receiving NPPV was comparable to the reference population group with chronic lung diseases who were not dependent on NPPV, indicating that if severe physical limitation occurs 
in advanced respiratory disease this does not necessarily lead to further mental limitation. Therefore, the common belief in domiciliary ventilator-dependent patients being mentally impaired due to severe physical limitations is not supported by our results. This finding corresponds to the observations of others $[4,8,25]$.

The results of the present study additionally demonstrate that mental health in patients receiving NPPV is affected by the underlying disease, since MANCOVA revealed that patients with COPD are more impaired in mental health than patients with kyphoscoliosis. This was demonstrated both by the summary measures and by the subscales of the SF-36. In addition to hypercapnic CRF patients with COPD usually suffer from additional impairments such as bronchospasm, chronic productive cough, hypoxemia, and cor pulmonale. This may explain why patients with COPD feel more impaired. In addition, CRF due to COPD is often associated with exacerbation with the need for hospitalization, and exacerbation requiring mechanical ventilation and exacerbation frequency have been shown to be related to impairments of HRQL in COPD [26, 27]. Further, HRQL was also dependent on the admission diagnosis 6 months after intensive care with COPD patients faring poorly [28]. Interestingly, in patients with Duchenne muscular dystrophy health perception and social aspects of SF-36 HRQL index have been reported as equivalent to those in other groups with nonprogressive disorders using NPPV [29], and patients with Duchenne muscular dystrophy had the overall best mental health in our study, even higher than the mental health of the general population despite severe physical limitations. However, this finding should be interpreted with caution due to the small number of patients with Duchenne muscular dystrophy included in the analysis, but might suggest coping strategies in this group.

To our knowledge, this is the largest study on HRQL in patients receiving NPPV, with 226 patients being enrolled. However, the SF-36 has been previously used in patients with NPPV. The study by Simonds and Elliott in which the SF-36 was sent to 116 of 180 patients receiving NPPV found the HRQL to be lower than in normals except in two subscales (Vitality and Mental Health), but HRQL was comparable to a group of patients in the United States with chronic disorders [4]. Patients with COPD and neuromuscular diseases had more limitations in physical function than patients with kyphoscoliosis, posttuberculosis sequelae, or poliomyelitis sequelae. SF36 scores on the subscales of patients in the study by Simonds and Elliott [4] were rather comparable to those in our study but were somewhat higher especially in the subscale of Role-Physical. Unfortunately, further comparisons are limited by the fact that detailed quantification of mean SF-36 subscale scores were not given, and that scores for PCS and MCS were not presented. In addition, the subgroup of patients who were sent the SF-36 questionnaire was not further characterized in that study, and no analysis investigating the effect of physical parameters on HRQL and no statistically based comparisons between different diagnostic groups were performed. Despite these limitations of the analysis of the SF-36 the study by Simonds and Elliott [4] was the first which presented SF-36 data of a large sample of patients receiving NPPV in comparison to reference populations. In addition, this study is excellent, since it was one of the first to present data on long-term survival in patients receiving NPPV.

Our study included only noninvasively ventilated patients, none who were tracheotomized. However, a large study on 168 predominantly neuromuscular patients concluded that noninvasive methods of ventilation were more convenient, entailed fewer adverse effects on speech, appearance, and comfort, and were preferred overall to tracheotomy in patients dependent on NPPV [30]. Therefore, the benchmark data presented here are valid for patients using noninvasive ventilatory strategies via face masks, but cannot be used for tracheotomized patients.

Elevated $\mathrm{PaCO}_{2}$ in patients with $\mathrm{CRF}$ has been found to be correlated with increased inspiratory load and decreased inspiratory muscle strength [31, 32], and it has been reported that long-term survivors of hypercapnic respiratory failure due to COPD had a significant decrease in $\mathrm{PaCO}_{2}$ during spontaneous breathing following NPPV, emphasizing the importance of maximal reduction in $\mathrm{PaCO}_{2}$ during ventilation and spontaneous breathing [2]. Therefore, it has been suggested that ventilatory therapy should be adjusted to achieve normalization of the arterial blood gases with the best comfort for the patient [33, 34]. Our data showed a good correlation between $\mathrm{PaCO}_{2}$ during NPPV and $\mathrm{PaCO}_{2}$ during spontaneous breathing following NPPV, suggesting that normalization of $\mathrm{PaCO}_{2}$ achieved by NPPV also results in a significant reduction in $\mathrm{PaCO}_{2}$ during subsequent spontaneous breathing. This finding is supported by other observations [35]. The majority of patients, including those with COPD, could be ventilated towards normocapnia, although patients with COPD had higher $\mathrm{PaCO}_{2}$ values during spontaneous breathing than the other patients. However, $\mathrm{PaCO}_{2}$ was not a predictor of HRQL in our study. Accordingly, $\mathrm{PaO}_{2}$ was also not a predictor of HRQL in our study, but HRQL has been shown to be related to the severity of hypoxemia in patients with severe COPD not dependent on NPPV in another study; however, this relationship was only detectable when using a disease-specific questionnaire [36]. Therefore, the arterial blood gas measurements were not predictive of HRQL in our study, but further evaluation is necessary to confirm this observation.

One limitation of the present study is the fact that HRQL was not measured prospectively before and after institution of NPPV. However, longitudinal studies including patients with CRF due to COPD have been con- 
ducted in the past that indicate only minor changes following NPPV $[3,7,9,10]$. The study by Sivasothy and coworkers [10] used the SF-36 prospectively and observed significant improvements only in one of the eight SF-36 domains (Role-Physical). In addition, SF-36 HRQL improved in one domain (Vitality) following the institution of NPPV in patients with amyotrophic lateral sclerosis, and here NPPV did not cause any reduction in HRQL despite disease progression [11]. It remains unclear, however, whether changes in HRQL are slight due to the nature of the disease or due to the non-conditionspecific instruments applied which might be not sensitive enough to detect changes in HRQL. Although it has been shown that changes in HRQL in patients with CRF can be assessed by using the SF-36 [37, 38], it has been pointed out that disease-specific instruments are most sensitive and most appropriate for clinical trials in which specific therapeutic interventions are being evaluated [12]. Therefore, we suggest that the SF-36, as administered in the present study, is appropriate for cross-sectional studies including patients receiving NPPV and comparing patients with various health statuses or diseases, but that changes in HRQL following establishment of NPPV and ventilator-associated impairment of health status may be assessed more precisely using disease-specific instruments. Therefore, we have additionally developed and validated a new questionnaire during the present study which has been specifically designed to measure HRQL in patients with severe respiratory insufficiency receiving NPPV, the Severe Respiratory Insufficiency (SRI) Questionnaire [24] (Windisch et al., in preparation). We believe that this questionnaire is suitable for future studies aiming at prospective evaluation of changes in HRQL following the institution of NPPV. In addition, a new, validated, and practicable questionnaire has recently been introduced which was specifically developed for patients with severe CRF receiving long-term oxygen therapy or NPPV, the Maugeri Foundation Respiratory 28-item set [39]. This questionnaire is currently being used in the Quality of Life Evaluation and Survival Study (QuESS) [40].

In conclusion, HRQL is significantly impaired in patients receiving NPPV compared to the general population. This is due primarily to limitations in physical health, but less to limitations in mental health, indicating that if severe physical limitation occurs in advanced respiratory disease, this does not necessarily lead to mental limitation. However, mental health is reduced more in patients with COPD than in those with kyphoscoliosis, but physical parameters were not predictive for SF-36 components, indicating that HRQL is influenced by the underlying disease, but not by physical parameters in patients receiving NPPV.

Acknowledgements This study was supported by Breas Medical AB. In addition, we thank Prof. David Christiani, Harvard School of Public Health, Boston, Mass., USA, for his assistance preparing the manuscript.

\section{References}

1. Bach JR, Alba AS (1990) Management of chronic alveolar hypoventilation by nasal ventilation. Chest 97:52-57

2. Leger P, Bedicam JM, Cornette A, Reybet-Degat O, Langevin B, Polu JM, Jeannin L, Robert D (1994) Nasal intermittent positive pressure ventilation Long-term follow-up in patients with severe chronic respiratory insufficiency. Chest 105:100-105

3. Meecham Jones DJ, Paul EA, Jones PW, Wedzicha JA (1995) Nasal pressure support ventilation plus oxygen compared with oxygen therapy alone in hypercapnic COPD. Am J Respir Crit Care Med 152:538-544

4. Simonds AK, Elliott MW (1995) Outcome of domiciliary nasal intermittent positive pressure ventilation in restrictive and obstructive disorders. Thorax 50:604-609
5. Anonymous (1999) Clinical indication for noninvasive positive pressure ventilation in chronic respiratory failure due to restrictive lung disease, COPD, and nocturnal hypoventilation - a consensus conference report. Chest 116:521-534

6. Mehta S, Hill NS (2001) Noninvasive ventilation. Am J Respir Crit Care Med 163:540-577

7. Elliott MW, Simonds AK, Carroll MP, Wedzicha JA, Branthwaite MA (1992) Domiciliary nocturnal nasal intermittent positive pressure ventilation in hypercapnic respiratory failure due to chronic obstructive lung disease: effects on sleep and quality of life. Thorax 47:342-348

8. Pehrsson K, Olofson J, Larsson S, Sullivan M (1994) Quality of life of patients treated by home mechanical ventilation due to restrictive ventilatory disorders. Respir Med 88:21-26

9. Perrin C, El Far Y, Vandenbos F, Tamisier R, Dumon MC, Lemoigne F, Mouroux J, Blaive B (1997) Domiciliary nasal intermittent positive pressure ventilation in severe COPD: effects on lung function and quality of life. Eur Respir J 10:2835-2839
10. Sivasothy P, Smith IE, Shneerson JM (1998) Mask intermittent positive pressure ventilation in chronic hypercapnic respiratory failure due to chronic obstructive pulmonary disease. Eur Respir J 11:34-40

11. Lyall RA, Donaldson N, Fleming T, Wood C, Newsom-Davis I, Polkey MI, Leigh PN, Moxham J (2001) A prospective study of quality of life in ALS patients treated with noninvasive ventilation. Neurology 57:153-156

12. Testa MA, Simonson DC (1996) Assessment of quality-of-life outcomes. N Engl J Med 334:835-840

13. Wood-Dauphinee S (1999) Assessing quality of life in clinical research: from where have we come and where are we going? J Clin Epidemiol 52:355-363

14. Higginson IJ, Carr AJ (2001) Measuring quality of life: using quality of life measures in the clinical setting. BMJ 322:1297-1300 
15. Ware JE Jr, Sherbourne CD (1992) The MOS 36-item short-form health survey (SF-36). I. Conceptual framework and item selection. Med Care 30:473-483

16. Ware JE Jr, Kosinski M, Gandek B, Aaronson NK, Apolone, G, Bech P, Brazier J, Bullinger M, Kaasa S, Leplege A, Prieto L, Sullivan M (1998) The factor structure of the SF-36 Health Survey in 10 countries: results from the IQOLA Project. International Quality of Life Assessment. J Clin Epidemiol 51:1159-1165

17. Chrispin PS, Scotton H, Rogers J, Lloyd D, Ridley SA (1997) Short Form 36 in the intensive care unit: assessment of acceptability, reliability and validity of the questionnaire. Anaesthesia 52:15-23

18. Ridley SA, Chrispin PS, Scotton H, Rogers J, Lloyd D (1997) Changes in quality of life after intensive care: comparison with normal data. Anaesthesia 52:195-202

19. Welsh CH, Thompson K, Long-Krug S (1999) Evaluation of patient-perceived health status using the Medical Outcomes Survey Short-Form 36 in an intensive care unit population. Crit Care Med 27:1466-1471

20. Eddleston JM, White P, Guthrie E (2000) Survival, morbidity, and quality of life after discharge from intensive care. Crit Care Med 28:2293-2299

21. Flaatten H, Kvale R (2001) Survival and quality of life 12 years after ICU. A comparison with the general Norwegian population. Intensive Care Med 27:1005-1011

22. Bullinger M (1995) German translation and psychometric testing of the SF-36 Health Survey: preliminary results from the IQOLA Project. International Quality of Life Assessment. Soc Sci Med 41:1359-1366

23. Bullinger M, Kirchberger I (ed) (1998) SF-36 Fragebogen zum Gesundheitszustand - Handanweisung. Hogrefe, Göttingen
24. Windisch W, Petermann F, Schucher B, Baumann H, Wiebel M, Matthys H, Freidel F (2001) The Severe Respiratory Insufficiency (SRI) Questionnaire: a specific measure of health-related quality of life in patients receiving home mechanical ventilation (abstract). Eur Respir J 18 [Suppl 33]:402S

25. Bach JR, Campagnolo DI, Hoeman $S$ (1991) Life satisfaction of individuals with Duchenne muscular dystrophy using long-term mechanical ventilatory support. Am J Phys Med Rehabil 70:129-135

26. Seemungal TA, Donaldson GC, Paul EA, Bestall JC, Jeffries DJ, Wedzicha JA (1998) Effect of exacerbation on quality of life in patients with chronic obstructive pulmonary disease. Am J Respir Crit Care Med 157:1418-1422

27. Ambrosino N, Bruletti G, Scala V, Porta R, Vitacca M (2002) Cognitive and perceived health status in patient with chronic obstructive pulmonary disease surviving acute on chronic respiratory failure: a controlled study. Intensive Care Med 28:170-177

28. Hurel D, Loirat P, Saulnier F, Nicolas F, Brivet F (1997) Quality of life 6 months after intensive care: results of a prospective multicenter study using a generic health status scale and a satisfaction scale. Intensive Care Med 23:331-337

29. Simonds AK, Muntoni F, Heather S, Fielding S (1998) Impact of nasal ventilation on survival in hypercapnic Duchenne muscular dystrophy. Thorax 53:949-952

30. Bach JR (1993) A comparison of long-term ventilatory support alternatives from the perspective of the patient and care giver. Chest 104:1702-1706

31. Criee CP, Neuhaus KL, Wilhelms E, Kreuzer H (1982) Mouth occlusion pressure in patients with chronic obstructive lung disease in stable state and in acute respiratory failure. Bull Eur Physiopathol Respir 18 [Suppl 4]:155-164

32. Begin P, Grassino A (1991) Inspiratory muscle dysfunction and chronic hypercapnia in chronic obstructive pulmonary disease. Am Rev Respir Dis 143:905-912

33. Leger P (1994) Noninvasive positive pressure ventilation at home. Respir Care 39:501-514
34. Leger P, Muir JF (1998) Selection of patients for long-term nasal intermittent positive pressure ventilation: practical aspects. In: Roussos C (ed) Mechanical ventilation from intensive care to home care. European Respiratory Society Journals, Sheffield, pp 328-347

35. Windisch W, Vogel M, Sorichter S, Hennings E, Bremer $\mathrm{H}$, Matthys $\mathrm{H}$, Virchow Jr JC (2002) Normocapnia during nIPPV in chronic hypercapnic COPD reduces subsequent spontaneous $\mathrm{PaCO}_{2}$. Respir Med 96:572-579

36. Okubadejo AA, Jones PW, Wedzicha JA (1996) Quality of life in patients with chronic obstructive pulmonary disease and severe hypoxaemia. Thorax 51:44-47

37. Jones PW, Bosh TK (1997) Quality of life changes in COPD patients treated with salmeterol. Am J Respir Crit Care Med 155:1283-1289

38. Bennett LS, Barbour C, Langford B, Stradling JR, Davies, RJ (1999) Health status in obstructive sleep apnea: relationship with sleep fragmentation and daytine sleepiness, and effects of continuous positive airway pressure treatment. Am J Respir Crit Care Med 159:1884-1890

39. Carone M, Bertolotti G, Anchisi F, Zotti AM, Donner CF, Jones PW (1999) Analysis of factors that characterize health impairment in patients with chronic respiratory failure. Quality of Life in Chronic Respiratory Failure Group. Eur Respir J 13:1293-1300

40. Carone M, Ambrosino N, Bertolotti G, Bourbeau J, Cuomo V, De Angelis G, Garuti G, Gasparotto A, Giamesio P, Ilowite J, Ioli F, Melchor R, Neri M, Nishimura K, Oliveira LV, Pierobon A, Ramponi A, Rochester C, Salajka F, Lauro IS, Singh S, Zaccaria S, Votto J, Zuwallack R, Jones PW, Donner CF, the QuESS Group (2001) Quality of Life Evaluation and Survival Study: a 3-yr prospective multinational study on patients with chronic respiratory failure. Monaldi Arch Chest Dis 56:17-22 